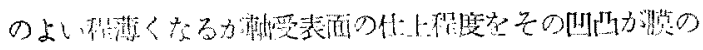

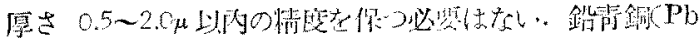

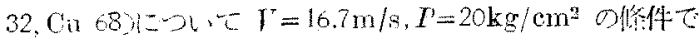

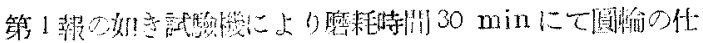

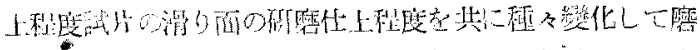

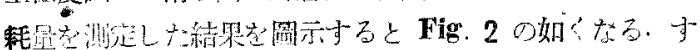

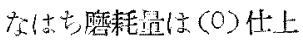

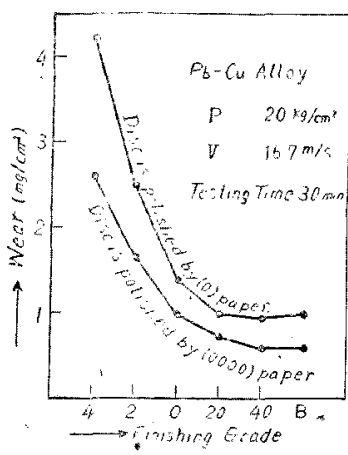

Fig. 2 Wear Resuits of $\mathrm{Pb}-\mathrm{Cu}$ Alloy.

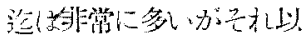

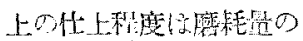

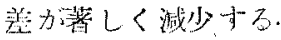

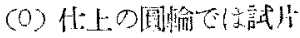

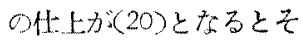

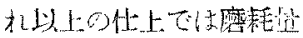
は间值でつて Buffing などは効果はない（40)

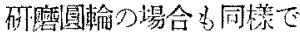
試片の(40)とBuffing と

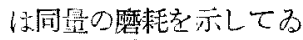
z.

\section{(2) Al 合金}

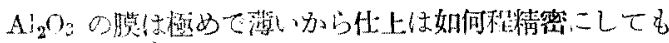
上いおけで古る殊純Alでは Tabje 2 に示した如く表

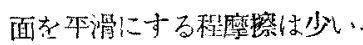

\section{(3) $\Lambda \mathrm{g}$ 及び $\Lambda \mathrm{g}$ 合金}

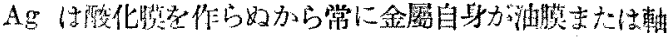

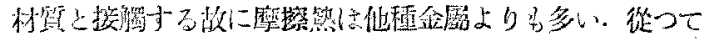

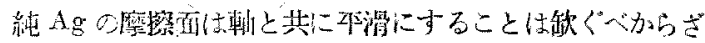

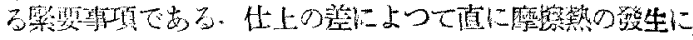
差艮生ずる，故に梘付に對しては非常に不安定であると言

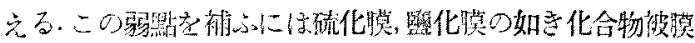

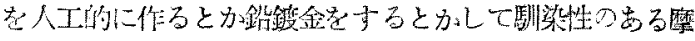

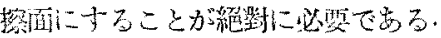

\section{III. 結霄}

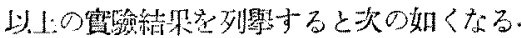

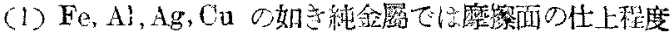
は精密な积摩檫は少い

（2）所謂則受合金は軸の忙上程度以上の精度に气の摩蔡

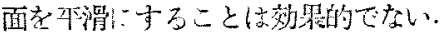

(a) Ag と Cast iron とは Fig. 1 の如〉䵇察と仕上程 度との阔倸方全く遂でるる。

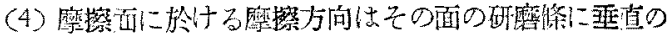

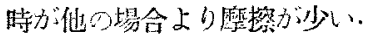

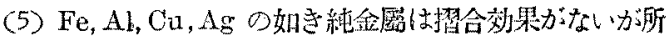

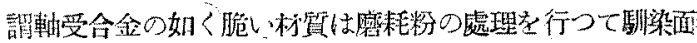
を作るため摺合は必要である。

\title{
軸受性能について(第6 報)*
}

水里昂昂些

Köichi Mizuno : On the Bearing Property of Metals and Alloys. (6th Report) The results of wear test on sime kinds of carbon steels and cast iron in combination with carbon steele and cast iron prove that the wear loss is proportional to the hardness variation of the rubbing surface. The harlness of rubbed surface is measured by the microscopic Vickershardmeter on $100 \mathrm{gram}$ kad. The surface hardness of steel increases on the low carbon side and decreases on the high carbon side. This phenomenon resembles the oxide film hardness reported in the 2 nd report. The oxide film generally protects abrasion but free oxide fiakes or grains accelerate wear and soft material that produces hard oxides can easily wear out harder steel. As a consequence of the inmrdinate hardness increase on the rubbing surface of carbon steel in certain conditions, it is supposed that there are not mily simple plastic deformation anl oxidation bat alsn quenching by radical heating and cosling.

(Receivel Janary 19.1949)

\section{I. 緒 言}

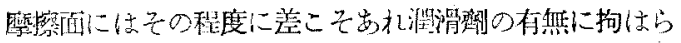

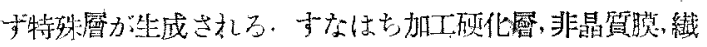

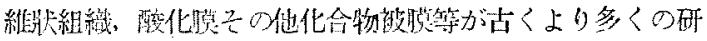

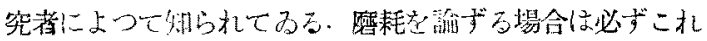

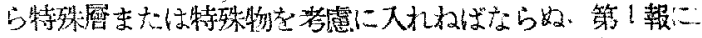

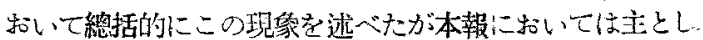

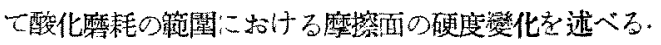

\section{II. 麾徖 加 エ}




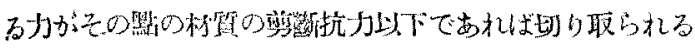

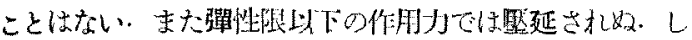
かし作用力が材留の强度より大なる時は取り去ら机まなは

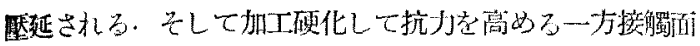

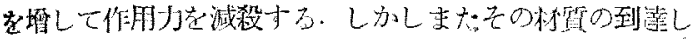

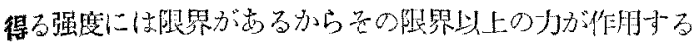

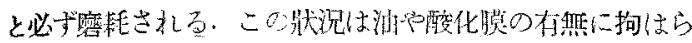

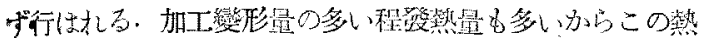

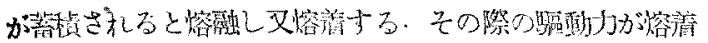

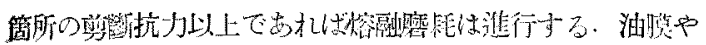

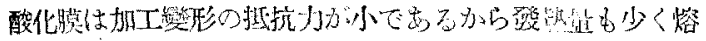

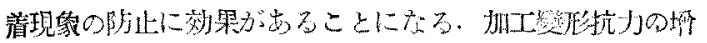

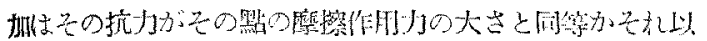

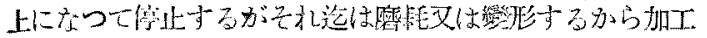

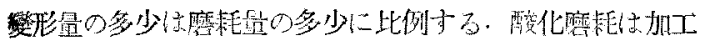

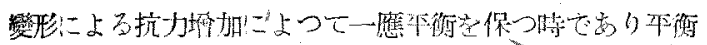

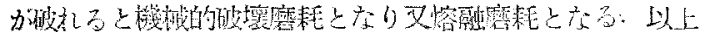

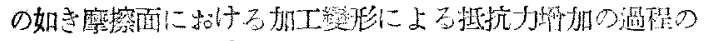

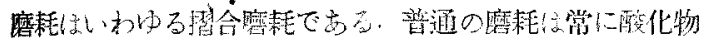

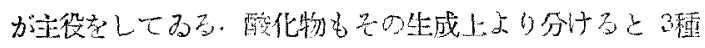

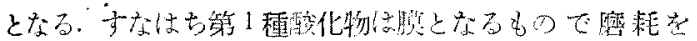

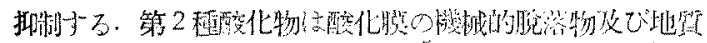

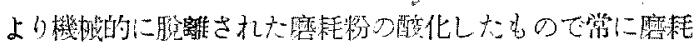

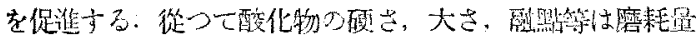

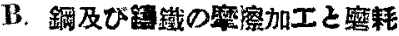 (1) 試馬薟要領之豫菕試䮩}

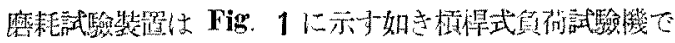

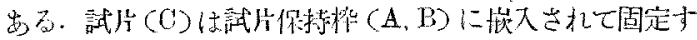

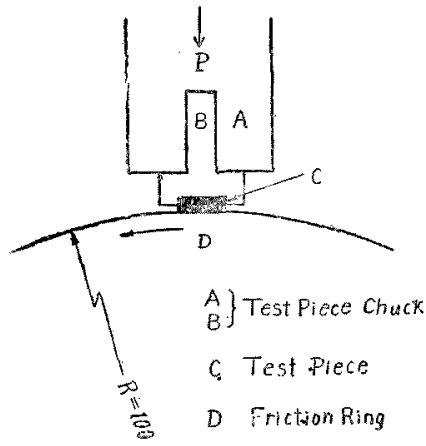

Fig. 1 Testing Apparatus.
る. 倠画は上部上り

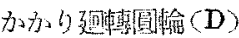
を試片によつて篹与 万. 圆輅の直倠 200 $\mathrm{mm}$ 試算は10 $\mathrm{mm} \phi$ メ3mm でせる。試 片は滑り而索平面に 仕上げて志去加ら最

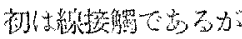
恋耗の進行と其に凹

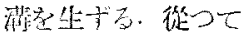
最初の線接触ては極

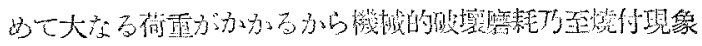

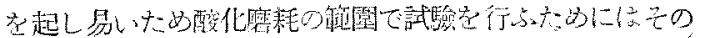

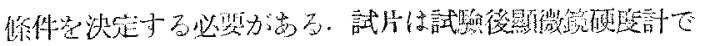

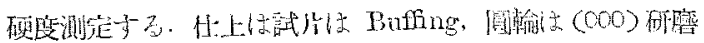

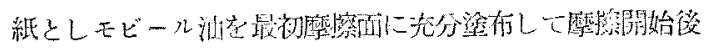

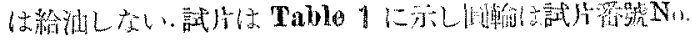
2 及び No.6と泟一材貿としふ。

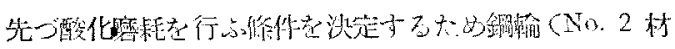

Table 1 Test Pieces.

\begin{tabular}{|c|c|c|c|c|c|c|c|c|c|}
\hline \multirow{2}{*}{ No. } & \multicolumn{6}{|c|}{ Chemical Composition ( $\%)$} & \multirow{2}{*}{$\begin{array}{c}\text { Heat } \\
\text { Treatment }\end{array}$} & \multirow{2}{*}{$\begin{array}{l}\text { Hardness } \\
\text { (Brinell) }\end{array}$} & \multirow{2}{*}{ Note } \\
\hline & $\mathrm{C}$ & $8 \mathrm{i}$ & $\mathrm{Mn}$ & $\mathrm{Cr}$ & $P$ & $\$$ & & & \\
\hline 1 & 0.23 & - & - & - & - & - & $600^{\circ} 2 \mathrm{hr}$ & 150 & OHA JES 1002 \\
\hline 2 & 0.38 & - & - & 一 & - & - & " & 180 & "I 1003 \\
\hline 3 & 0.55 & - & - & - & - & - & $" \prime$ & 185 & 1004 \\
\hline 4 & 0.78 & - & - & - & - & - & $" \prime$ & 255 & $\overline{0}$ \\
\hline 5 & 1.21 & 0.30 & - & 1.52 & - & - & $"$ & 260 & Bearing Ball steei \\
\hline 6 & 3.15 & 1.80 & 0.59 & - & - & 0.12 & - & 240 & Pearlitic \\
\hline $7 !$ & 3.15 & 1.80 & 0.59 & - & 一 & 0.12 & - & 740 & White Pig \\
\hline 8 & 0.37 & 2.30 & - & 12.10 & - & - & $\begin{array}{r}1000^{\circ} 3 \mathrm{~min} \\
850^{\circ} 9 \mathrm{cmin}\end{array}$ & 380 & OH JES 1302 \\
\hline 9 & \multicolumn{7}{|c|}{ Al $93, \mathrm{Mg} 7$, Cast Piece Anodic film } & 380 & 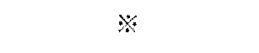 \\
\hline
\end{tabular}

※ Oxalic acid 3\%, Bath temp. 25, Treating time 60min, A.O. $90 \mathrm{~V}$, D.0.30V, together.

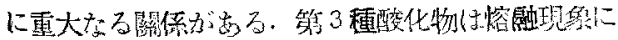
より急激に酸化されたもので膜となりまたは籵朴と なり磨耗抑制したり促推したりする。哎となると

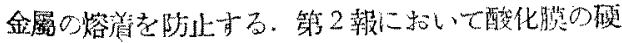

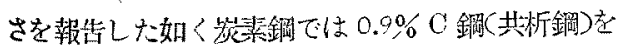

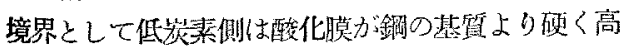
炭素侧は軟くなる。本報に打ける磨耗試驗結果も全 くこれと同一の状吼示してるる。低岁素㒋では摩 䍉面の硬㢃上帠は或る條件下では诸しく單なる加工 硬化とは㹲へられず，また酸化膜の硬ざでないの

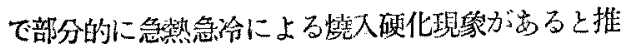
渄される。

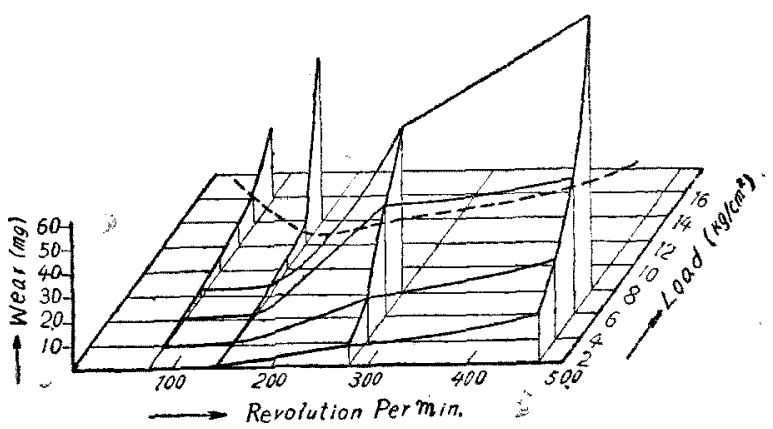

Fig. 2 Wear Losg Figure. 
質) と試片 No.1 との組合によつて荷重と滑り速度とを變

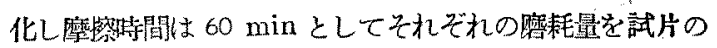
重量減より测定した結果は Fig. 2 となつた。太嘿線より

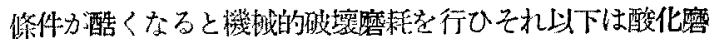
耗を行ふっ。これにより試驗實行に好道な他の條件をむ考虑 して本試驗は迥轉僌 475 r.p.m. 荷直 $2 \mathrm{~kg}, 4 \mathrm{~kg}, 6 \mathrm{~kg}$ とし な.

\section{(2) 試驗結果とその考察}

Fig.3 及び Fig.4 は鉦榆及び䥂鐵輸に對する各種 $0 \%$ の材質の $120 \mathrm{~min}$ 後の磨耗量曲面を示し Fig. 5 Fig. 8 は

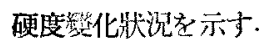

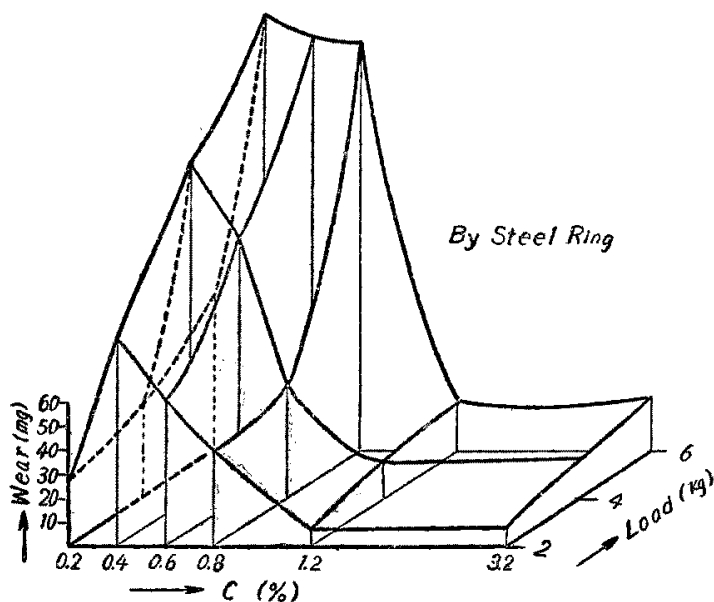

Fig. 3 Wear Loss in Various Conditions.

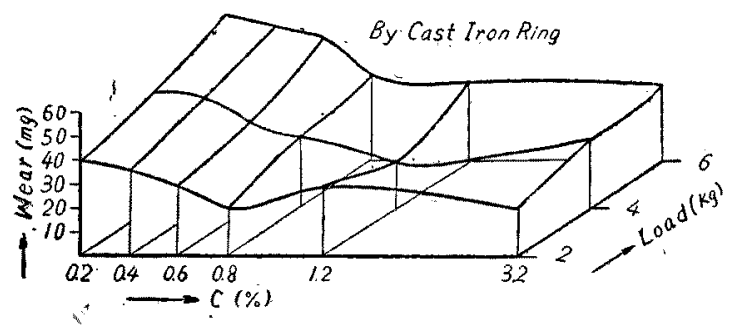

Fig. 4 Wear Loss in Various Conditions.

\section{(a) 磨耗量}

Fig. 3 にむいて同種の 鋼同志の喠耗量が最大である.

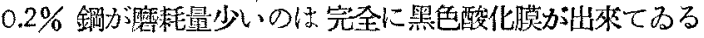

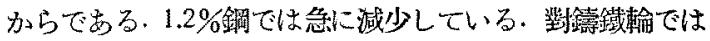
常に摩㨳面は酸化してるる．0.8\% 鋼が最少であつて $0.2 \%$ 鐗は最大である. $6 \mathrm{~kg}$ では $0.2 \%$ 銅の厚い酸化膜が却つて 眯耗量を促蕉してるる。こ扎は酸化膜の脱落による(第 2

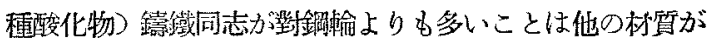
同志僴で多いのと其通に考へられる.酎熱不鋯鋼の酸化膜 は薄い、䇢でするが對鐸輪では磨耗量ゔ多い，この場合は機

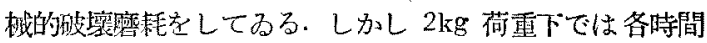

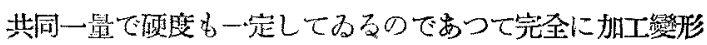

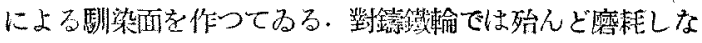
い. Al 合金の陽極酸化慕は $2 \mathrm{~kg}$ 荷重では膜は全く傷害さ

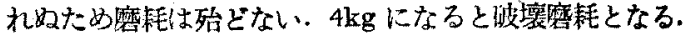
白銑試片は鑄瀻と同樣である。

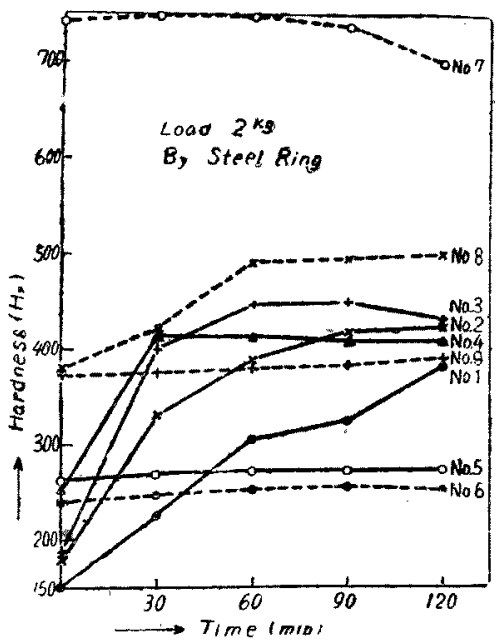

Fig. 5 Surface Hardness in Various Materials.

\section{(b) 硬度變化}

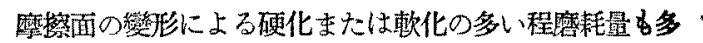
い.Fig. 5 及び Fig. 6 の對鍊輸の場合 C\%の少い程硬化 度が多くまた一定硬度に落付迄の時間が長い，2kg 荷重て は No. 1 \&o. 2 \&硬化の鉒上に在り 6kg で No. 1 は $150 \rightarrow 525$, No.2は $180 \rightarrow 470$ となり No.1よりも硬化度 は少い，更に $\mathrm{C} \%$ が聕寸と到達硬度は更に低いが $30 \mathrm{~min}$ にして一定値に落付いてるる. No. 5 は $2 \mathrm{~kg}$ では最初加 一定値となつてるるが $6 \mathrm{~kg}$ になると却つて軟化する。等 鐵も $2 \mathrm{~kg}$ よりは $6 \mathrm{~kg}$ の方か漱化度は多い. 白銑む同樣て

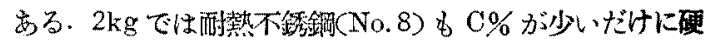
化能は多い.No，9の陽挭酸化被膜は當然硬度變化は無い

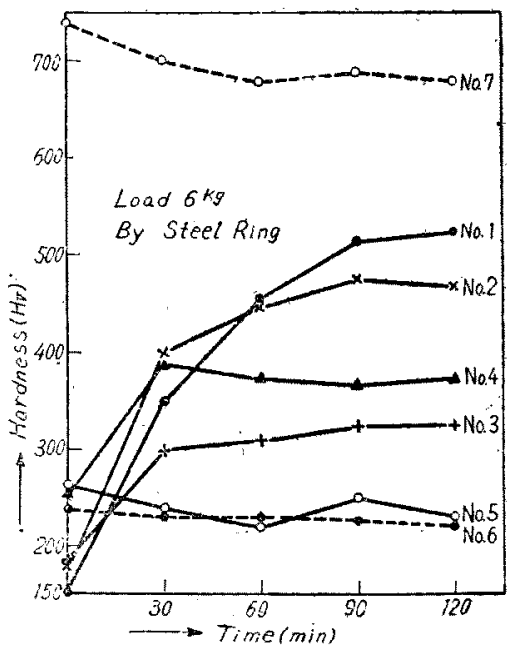

Fig.6 Surface Hardness in Variotis Materials. 


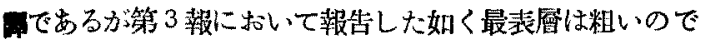

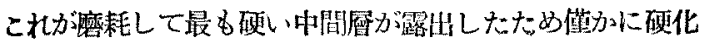
現鱼を呈してるる.

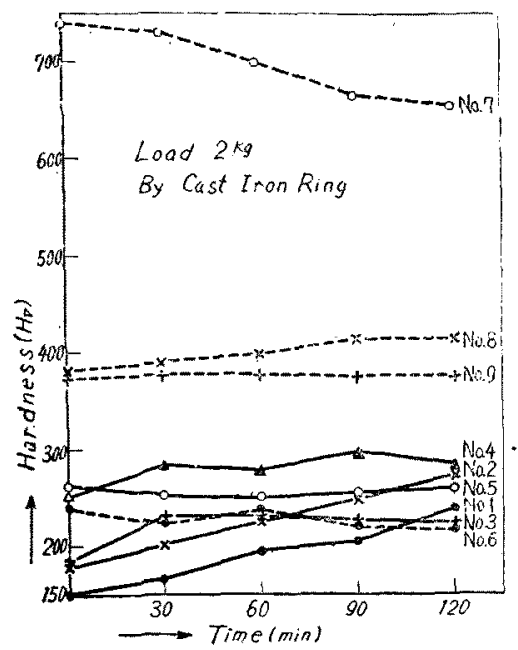

Fig. 7 Surface Hardness in Various Materials.

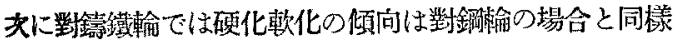

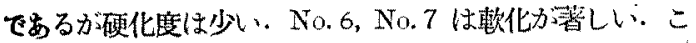
れら硬度の變化に共通した事は變化の多い程磨耗も多く硬

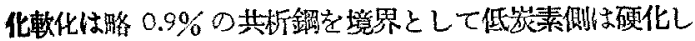
高炭素側は軟化ししが $0.9 \%$ より距離の多い程變化が多 い. 到洋硬度は材質と條件によつて一定してるる如く 考へられる. 第 2 報に招いて報告した酸化膜の硬度と材質

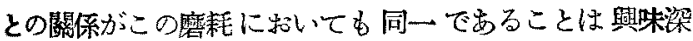
い. $2 \mathrm{~kg}$ て對鋼輸の場合 No.8 (不銹鋼) は No.2 (0.4\%

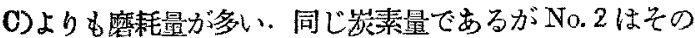
酸化膜によつて磨耗索防此してるる。. No. $2(0.4 \% \mathrm{C})$ 肢

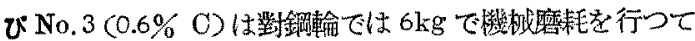
るる(第 2 種酸化物) これに反し No. 1 は完全な黑色酸化
膜で掩はれ磨耗も少い(第 1 稙酸化物)叉No.8 と No.9は 同し硬度であるが硬度變化の多い、No. 8 カ嚰耗は多い，

No. 1 の硬度の大なることは完全な黑色酸化膜の硕化と見

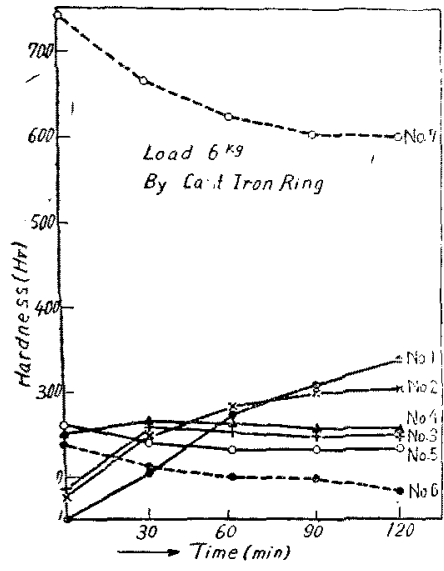

Fig. 8 Surface Hardness in Various Materials て差素へないが他 の試片に额ける硬 化尉の大さ老胃る とこの硬化は酸化 膜や扣工硬化によ るものとは胁して 斷じ得ない。酸化 膜の硬度は嘅に敨 告したが林留のみ でその硬度が 180 上り 400 万至 500 になることはな い, 又如何程冷間 歷延してるかかる 繁化は未げ確認さ 扎てるない，從つ て Fig. 5 及び Fig.6 に於ける No. 2，No.3，No.4 の如き

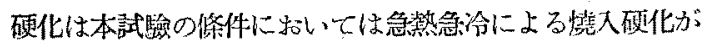
行はれた多つと推測することが出來る。

\section{III. 结}

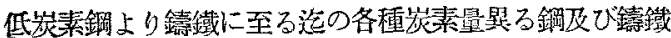
についてその磨耗量と摩擦面の硬度變化を試䲆した結果共 析成分を境界としてそれらの狀況が著しく孫ることが物つ

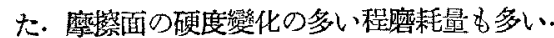

寸なはち磨耗を少くするには加工戀形双は硬度變化の少 い摩祭面とすることが必丞である・燒大効果の方る鋼は或

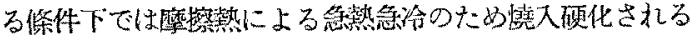
ととる岁ると考へられる。

\section{ミシン用各種金屬材料の磨耗に關する實驗}

安藤修二*沼“津, 正*

Syūzi Andō and Tadashi Numazu : Some Experiments on the Wear of Metals for the Sewing Machine. There are many friction parts in a searing machine for housebold use and the wear by friction influences the action, sound and vibration of it. The influences of the kind, microstructure, case bardening and surface roughness of metals upon the wear of friction parts were tested ; the results are briefiy summarised as follows :

(1) No great difference was noticed between the pearitic cast iron and ferritic cast iron in the amount of wear in wet friction.

(2) In the cases of water quenching after the heating by high frequency current and hard 